\title{
CONSCIENTIZAÇÃO SOBRE O TRANSTORNO DO ESPECTRO AUTISTA (TEA): UM RELATO DE EXPERIÊNCIA DO PROJETO "CRIAR PARA INFORMAR"
}

\author{
Nathalia de Oliveira Pires \\ Universidade Estadual do Ceará \\ nathaliapires13@gmail.com \\ Giovana Barroso de Melo Rios \\ Universidade Estadual do Ceará \\ giovana_bmrios@hotmail.com \\ Juliana Ciarlini Costa \\ Universidade Estadual do Ceará \\ juliana.ciarlini@aluno.uece.br \\ Lucas Lessa de Sousa \\ Universidade Estadual do Ceará \\ lucas96lessa@gmail.com \\ Raquel Matoso Freire \\ Universidade Estadual do Ceará \\ quelmatosof@gmail.com

\section{Tatiana Paschoalette Rodrigues Bachur \\ Universidade Estadual do Ceará tatiana.bachur@uece.br \\ Gislei Frota Aragão \\ Universidade Estadual do Ceará gislei.frota@uece.br}

\begin{abstract}
Resumo
O presente ensaio tem por objetivo relatar a relevância do projeto "Criar para informar", realizado pelo Grupo de Estudos em Neuroinflamação e Neurotoxicologia - GENIT/UECE, por meio de duas estratégias: (a) participação em eventos públicos com a apresentação de uma canção autoral e (b) uso de uma mascote virtual nas redes sociais para popularizar informações sobre o autismo. Em dois eventos sobre o Transtorno do Espectro Autista, realizados em abril de 2019, o projeto de extensão "Criar para Informar" apresentou a canção autoral "Pedacinhos", que chama atenção para a conscientização sobre o trastorno. Como resultado, a canção mostrou-se, nas duas ocasiões, uma ferramenta de engajamento do público presente, gerando empatia e resgatando a atenção para a temática exposta. Além disso, os materiais digitais usando a ilustração de uma mascote vitrual do grupo obtiveram êxito, uma vez que apresentaram informações relevantes de maneira didática e ilustrativa, as quais contribuíram para uma comunicação eficaz direcionada à população em geral. Conclui-se que a introdução deelementos artísticos, seja via presencial ou midiática, são práticas bem recebidas pelo público e contribuem para a popularização do conhecimento científico.
\end{abstract}

Palavras-chave: Educação em Saúde. Mídias Sociais. Música. Autismo. 


\title{
AWARENESS ON AUTISM SPECTRUM DISORDER (ASD): AN EXPERIENCE REPORT OF THE “CREATE TO INFORM" PROJECT
}

\begin{abstract}
The current essay aims to report the relevance of the project "Create to inform", carried out by Neuroinflammation and Neurotoxicology Study Group - GENIT/UECE, through two strategies, participation in public events with a presentation of an authorial song and the use of a social media mascot to popularize information about autism spectrum disorder. In two events on the theme of autism, both held on April 2019, the extension project "Create to inform" featured an authorial song "Pedacinhos", which calls attention to the awareness about autism. As a result, the song performed as a tool of engagement from the present audience, generating empathy and drawing attention to the theme exposed. In addition, the digital materials published by students, as they presented relevant information in a didactic and illustrative manner, contributed to an effective communication directed to the general population. So, the introduction of artistic elements, either on or offline, are practices well received by the public and contribute to the popularization of scientific knowledge.
\end{abstract}

Keywords: Health Education. Social Media. Music. Autism.

\section{CONCIENCIA SOBRE EL TRASTORNO DEL ESPECTRO DEL AUTISMO (TEA): UN INFORME DE EXPERIENCIA DEL PROYECTO "CREAR PARA INFORMAR"}

\begin{abstract}
Resumen
El propósito de este ensayo es informar la relevancia del proyecto "Crear para informar", llevado a cabo por el Grupo de Estudio sobre Neuroinflamación y Neurotoxicología - GENIT / UECE, a través de dos estrategias: (a) participación en eventos públicos con la presentación de una canción de autor y (b) usar una mascota virtual en las redes sociales para popularizar la información sobre el autismo. En dos eventos sobre el trastorno del espectro autista, celebrados en abril de 2019, el proyecto de extensión "Crear para informar" presentó la canción de autor "Pedacinhos", que llama la atención sobre la conciencia del trastorno. Como resultado, la canción demostró ser, en ambas ocasiones, una herramienta para involucrar a la audiencia, generar empatía y restaurar la atención al tema expuesto. Además, los materiales digitales que utilizaron la ilustración de una mascota grupal tuvieron éxito, ya que presentaron información relevante de manera didáctica e ilustrativa, lo que contribuyó a una comunicación efectiva dirigida a la población en general. Se concluye que la introducción de elementos artísticos, ya sea en persona o a través de los medios, son prácticas bien recibidas por el público y contribuyen a la popularización del conocimiento científico.
\end{abstract}

Palabras clave: Educación en Salud. Redes Sociales. Música. Autismo. 


\section{INTRODUÇÃO}

O TEA tem por definição um grupo de distúrbios do desenvolvimento neuropsicomotor, caracterizado por comprometimento na comunicação e interação social, além de comportamentos atípicos da criança. É descrito também como uma manifestação de prejuízos nas funções executivas e motoras, o que inclui déficit cognitivo (SAMPAIO et al., 2015).

A arte surge, nesse contexto como ferramentas de inclusão social e estímulo às interações sociais. Uma das manifestações de arte é a música, um estimulador neuronal desde os primeiros anos de vida. Os componentes da música, como ritmo, melodia e conexões entre som e movimento, estimulam o processamento de informações pelas crianças. Outrossim, contribui para o desenvolvimento das emoções, por meio da ativação do sistema límbico, cuja consequência é a mudança de diversas conexões cerebrais (ÁVILA, 2015; SAMPAIO et al., 2015).

Sob diferente perspectiva, as redes sociais constituem uma outra ferramenta promotora da comunicação interpessoal, as quais utilizam a divulgação global de informações A mensagem transmitida virtualmente tem como objetivo a propagação de forma massiva, e é construída de acordo com as características de seu público alvo Os usuários são fundamentais durante o desenvolvimento do conteúdo digital, pois, através da filtragem de informações, da seleção de conteúdo dentro de seus interesses e do uso dos dispositivos de pesquisa, irão delimitando e influenciando o que será exposto ao público (RECUERO, 2012; ALLEGRETTI et al., 2012; KOEHLER et al.,2015).

O termo rede social transmite claramente a ideia de união na coletividade, porquanto, por meio da conectividade, favorece o surgimento e a constância das conexões dinâmicas preservadas pelo sistema de redes sociais. Esses sites são serviços que permitem a construção de um perfil público ou semipúblico dentro de um sistema fechado, e são mantidos até a sua retirada da rede pelos usuários da ferramenta Grande parte dos serviços é ofertado de forma gratuita através de um computador ou celular, desde que haja acesso à internet; os dois exemplos mais comuns dentro dessa perspectiva são o Facebook e o Instagram (RECUERO, 2012; ALLEGRETTI et al., 2012; KOEHLER et al.,2015).

As redes sociais virtuais participam das novas tendências educacionais na cibercultura e estão direcionadas à aprendizagem participativa, ao compartilhamento, à comunicação e à aprendizagem interativas e à possibilidade de transgressão do currículo escolar tradicional. Dentro dessas redes, há interação entre humanos e tecnologias dando origem ao conectivismo adaptado à era digital. A teoria do conectivismo afirma que a 
habilidade do aprendizado de cada indivíduo depende da sua capacidade de se conectar a informações específicas e aos nós das redes digitais que lhe permitam aprender mais. A teoria é fundamentada por princípios, os quais resumidamente apoiam: a construção da relação entre aprendizagem e conhecimento dentro da diversidade de opiniões e pelas fontes de informação; o fornecimento de aprendizado através do meio digital; a conservação das conexões, a fim de dar continuidade ao processo de facilitação do aprendizado; a habilidade em conectar as diversas áreas, ideias e conceitos; a autonomia de julgamento e entendimento sobre as informações recebidas, como parte do processo de construção do conhecimento (RECUERO, 2012; ALLEGRETTI et al., 2012; KOEHLER et al.,2015).

O Facebook e o Instagram são redes sociais online que proporcionam a interação e participação de diversas faixas etárias, em que há administração e compartilhamento de mídias sociais (mensagens, fotos, vídeos, links), discussões em grupo ou acompanhamento de informações por meio da página de sites (ALLEGRETTI et al., 2012). Cada indivíduo tem a liberdade de seguir as contas de usuários que utilizam tais redes, de acordo com suas preferências (ALLEGRETTI et al., 2012). Um número significativo da população acessa essas redes sociais por meio de dispositivos móveis, como o smartphone (ALLEGRETTI et al., 2012). Segundo dados do IBGE de 2017, o celular é o equipamento mais utilizado para acessar à internet (98,7\%); em seguida está o microcomputador (52,3\%). 69,8\% dos que utilizam a internet possuem 10 anos ou mais de idade (BRASIL, 2017). A tecnologia móvel transforma as relações do homem com o mundo construindo novos parâmetros de sociabilidade, comunicação, produção intelectual e prática (ALLEGRETTI et al., 2012).

O meio digital, como ferramenta de comunicação e informação, proporciona uma interconexão entre o ser humano e o grande acervo de conhecimentos distribuídos online. Este exercita forte influência social e educacional mediante a oferta de recursos pertinentes à construção do conhecimento científico, senso crítico e senso comum de cada indivíduo (RECUERO, 2012; CERIGATTO, CASARIN, 2017).

Sob uma perspectiva histórica, o rádio e a televisão intensificaram a cultura de massa, até a chegada da internet e da cultura digital (LUCENA, 2016; ALLEGRETTI et al., 2012; VIÉGAS et al., 2017). Em seguida, as tecnologias da informação e comunicação (TIC) introduziram-se nas diferentes esferas sociais, nas últimas décadas do século XX (LUCENA, 2016; ALLEGRETTI et al., 2012; VIÉGAS et al., 2017). Já no século XXI, estas foram consolidadas devido ao uso intenso das tecnologias móveis e das redes sociodigitais, permitindo-se mobilidade às ações de transmitir informação, interagir, 
produzir e publicar, através dos tablets, notebooks, smartphones e outros dispositivos móveis (LUCENA, 2016; ALLEGRETTI et al., 2012; VIÉGAS et al., 2017). Essas tecnologias viabilizaram novas formas de comunicação, de aprendizagem, de disseminação de conteúdos e de culturas digitais, já que são desprendidas de lugares fixos e utilizam diferentes linguagens, novas técnicas, procedimentos, métodos e regras incorporadas ao ambiente informacional (LUCENA, 2016; ALLEGRETTI et al., 2012; VIÉGAS et al., 2017).

O atual cenário político e socioeconômico é desafiador, pois não permite que as várias classes sociais participem do total processo de aprendizagem de forma democrática Diante disso, o educador precisa se reinventar dentro do processo de ensino, buscando autonomia e apoio de outros educadores e de seus educandos Com o advento da cibernética, da informática e da eletrônica, os sistemas de informações configuram-se como provedores educacionais, permitindo que os educadores e educandos disseminem o conhecimento dentro dos mais variados espaços geográficos, diluindo as barreiras que privam a população da sabedoria social, cultural, tecnológica e cientifica (SANTOS; SANTOS, 2014). Os atuais espaços de estudo buscam adaptações aos novos modelos educacionais. São abertos, não lineares e se organizam de acordo com os objetivos e contextos dentro da singularidade e evolução do coletivo social (SANTOS; SANTOS, 2014; ALLEGRETTI et al., 2012).

Diante desse cenário, o presente trabalho tem como objetivo relatar a experiência obtida no projeto de extensão Criar para Informar, vinculado ao Grupo de Estudo em Neuroinflamação e Neurotoxicologia (GENIT), com registro institucional junto à Universidade Estadual do Ceará (UECE).

\section{METODOLOGIA}

O projeto Criar para Informar utilizou duas estretégias para a disseminação de informações acerca do TEA.

A primeira fora a música, que, nesse âmbito, apresenta diversos benefícios, um deles o de permanecer no inconsciente psíquico, produzindo efeitos emocionais mais duradouros (SILVA, 2005). Essa ferramenta foi aplicada em eventos comunitários, os quais visam a reforçar valores sociais e dispor informações acessíveis, além de disporem de outras características para o benefício coletivo (MAGALHÃES et al., 2016). A 
participação em eventos constitui-se como um importante instrumento de divulgação, já que há a reunião de várias pessoas com objetivos e propósitos em comum.

A segunda estratégia corresponde ao processo de construção de uma figura animada (mascote) destinada à divulgação de informações nas redes sociais Facebook $^{\circledR}$ e Instagram $^{\circledR}$. Essa prática é crescente nos âmbitos acadêmico, cientifico e social, e objetiva o uso das redes sociais para propósitos comunicativos, informativos e educacionais.

O primeiro evento em que se utilizou a música foi elaborado pela Associação Pintando o Sete Azul, uma organização beneficente que se responsabiliza em levar à sociedade uma melhor compreensão do TEA e de todas as particularidades de uma criança em tal condição. Ele ocorreu nos dias 12, 13 e 14 de abril de 2019, realizado em um shopping de Fortaleza. Lá vários palestrantes trouxeram diversas visões sobre o TEA, o abordando entre as diferentes áreas do conhecimento. O projeto "Criar para informar" fez sua participação na abertura do evento, dia 12 de abril, com a música "Pedacinhos" (Quadro 1), elaborada pelo grupo no ano de 2018, que, após intensa divulgação em mídias sociais, chegou à organização. A música foi cantada por um participante do projeto com auxílio da melodia em playback, e foram distribuídos vários panfletos com a letra para auxiliar o público no acompanhamento.

Quadro 1 Letra da música "Pedacinhos"

\begin{tabular}{|c|} 
Pedacinhos \\
Tenho um segredo pra te contar \\
Mas você vai ter que ajudar a desvendar \\
O mistério que é ver o mundo assim \\
Pedacinho a pedacinho todinho pra mim \\
Tem um pedacinho que quer te amar \\
Mas logo de cara não sei expressar \\
Se olho nos olhos, me perco total \\
Não fique sem jeito, pra mim é normal \\
Tem outra pecinha querendo encaixar \\
O que estou sentindo não sei te falar \\
Eu tenho desejos, você pode ver \\
O que eu não consigo é dizer a você \\
Eu sei, não é fácil me compreender \\
Mas com seu amor vou te surpreender \\
Pedaços não me faltam pra eu te completar \\
E é com seu amor que nós vamos juntar \\
Tem um pedacinho que quer te amar \\
Mas logo de cara não sei expressar \\
Se olho nos olhos, me perco total \\
Não fique sem jeito, o autismo é normal \\
\end{tabular}

Fonte: T.P.R.B., G.F.A., L.L.S., R.X.O. e J.C.C. 
O segundo evento que contou com a participação do projeto foi o II GENIT-Talk Seminário em Autismo, promovido pelo GENIT, que contou com a participação de cerca de 200 pessoas, dentre eles, profissionais, pais de indivíduos com TEA e participantes de associações em prol da causa, incluindo algumas crianças com essa condição. O evento foi realizado no dia 26 de abril de 2019, dividido em dois momentos, um no período da manhã e outro no período da tarde. O projeto "Criar para informar" foi convidado para apresentar a música na abertura das atividades da tarde, da mesma forma utilizada no evento anterior, apresentada por um participante do projeto, acompanhado pela melodia com playback. Além disso, foi distribuída, dentro do kit do evento, a letra da música em panfletos.

A mascote virtual foi desenvolvida em 2019, a pedido dos professores coordenadores do GENIT junto a uma empresa de comunicação e mídias digitais. O trabalho foi realizado levando em consideração o logotipo do grupo (Figura 1) e as cores encontradas nele (azul, laranja e branco). Após a finalização do desenho (Figura 2), este foi apresentado ao grupo, que o batizou de "Genitinho".

A principal razão de sua criação fora a necessidade de uma representação virtual para a ideia de propagar informações curtas, didáticas e bem-humoradas que pudessem ser veiculadas semanalmente nas redes sociais $\left(\right.$ Facebook $^{\circledR}$, Instagram $^{\circledR}$, Twitter $^{\circledR}$ e site do GENIT). Essa atividade busca transmitir informações de forma lúdica, acessível e interativa à população acadêmica e leiga, em qualquer região do mundo onde se tenha acesso às redes sociais do grupo. Desta forma, estava criado o projeto "GENIT informa", protagonizado pelo "Genitinho".

Os estudantes pertencentes ao GENIT participaram de uma seleção, em que fora escolhido o responsável pela realização das publicações do GENIT Informa. Até o mês de junho de 2019, um aluno da graduação de medicina da UECE, gerenciou o "GENIT informa", sendo, portanto, responsável pela criação de mídias sociais (texto e fotografia) que abordassem assuntos relacionado ao TEA, totalizando a publicação de três mídias. Depois desse período, no mês de agosto de 2019, foi realizada uma nova seleção para escolher outro aluno que ficasse à frente do "GENIT informa". A tarefa ficou a encargo de uma acadêmica do curso de enfermagem da UECE.

O layout das imagens da mídia social foi reformulado pela nova administradora, a fim de trazer uma estrutura que abrangesse uma maior quantidade de informações, mas que ainda fosse executada de forma lúdica e objetiva. Foi adicionado ao conjunto de informações, o "Ler Para (se) Informar", que pode ser descrito como uma forma de instigar a população à leitura de livros paradidáticos que abordem temas pertinentes ao TEA. O 
novo layout foi criado por meio do programa Power Point Microsof ${ }^{\circledR}$, utilizado para criação/edição e exibição de apresentações gráficas.

Para a construção das publicações referentes ao mês de agosto de 2019, foi consultada a base de dados Google Acadêmico e utilizadas as palavras-chave "transtorno do espectro autista", "inclusão social" e "inclusão escolar". Os critérios de inclusão foram artigos publicados entre 2015 e 2019, no idioma português. Os critérios de exclusão foram artigos publicados em outros idiomas e fora do período estabelecido. Ao final, foram selecionados dois artigos para compor de forma objetiva as publicações sobre "autismo e inclusão".

\section{RESULTADOS}

\section{A música no projeto Criar para Informar}

A música "Pedacinhos" mostrou-se, em ambos os eventos, uma ferramenta para o engajamento do público presente. No evento "GENIT TALK - Seminário sobre Autismo", onde a maioria do público - representado por figuras parentais de indivíduos com TEA possuía vínculo emocional com o tema principal da palestra, percebeu-se que a apresentação do material artístico em questão funcionou como um instrumento gerador de empatia e, por conseguinte, de resgate de atenção. Tal percepção embasou-se nos comentários posteriores por parte do próprio público, no tocante a trechos da música que geraram identificação pessoal. No evento "Exposição Fotográfica - Autistas Eles Crescem", foi notória forma como a apresentação da música chamou a atenção dos transeuntes dentro do centro de compras onde fora realizado, fato que se prova no aumento da quantidade de pessoas que frequentaram a exposição durante e após a apresentação ao vivo.

Ambos os eventos foram, ao final, positivamente avaliados em conversas informais e o GENIT, metonimicamente representado pela música "Pedacinhos", gerou muito interesse daqueles que ainda não o conheciam.

\section{As mídias digitais na divulgação do conhecimento científico}

A mascote virtual "Genitinho" desenvolveu-se dentro da necessidade da criação de um objeto que representasse o projeto de extensão do GENIT, "Criar para Informar", dentro das redes sociais, a fim de alcançar o público online com acesso à internet e às redes do mundo todo. 
O “Criar para Informar” tencionou levar informações para a população em geral acerca de cuidados com as doenças que afetam o sistema nervoso central, com o foco principal no TEA. A disseminação das informações prioriza que cada conteúdo seja compartilhado de forma lúdica, acessível e interativa, e passe por um processo de pesquisa correto, em páginas devidamente fundamentadas na literatura científica. O material instrutivo é compartilhado nas redes sociais: Facebook ${ }^{\circledR}$, Instagram $^{\circledR}$, Twiter $^{\circledR}$ e site do Genit.

Nessa perspectiva, as redes sociais do GENIT totalizam a marca de no mínimo 5.832 seguidores nacionais e internacionais, contando apenas Instagram $^{\circledR}$ e Facebook $^{\circledR}$ (2.509 e 3.323 seguidores, respectivamente), demonstrando um alto nível de alcance, ampliando as possibilidades, comprovando que a transmissão de conteúdo de qualidade por meio das tecnologias da informação e comunicação - TIC não é mais uma ação exclusiva dos profissionais de comunicação, e sim uma ação multiprofissional (TRIGO, 2018).

Nesse cenário, uma vez por semana é publicada uma postagem (Figura 3), composta por uma ou mais fotografias, acompanhadas por textos que descrevem um assunto relacionado ao TEA. Tal postagem é representada sempre pela mascote virtual "Genitinho". A primeira mídia trouxe o questionamento "Autismo é doença?"; a segunda mídia discorreu sobre "Quais as características do autismo?”; a terceira mídia abordou o tema "Como reconhecer os comportamentos típicos do TEA?"; a quarta mídia (Figura 4 e 5) trouxe à tona "Autismo e Inclusão" e, ao contrário das anteriores, foi apresentada sob um layout diferente do até então utilizado: em vez de apenas uma imagem foram postadas 5 dentro da mesma publicação. A última imagem dessa postagem trazia uma nova proposta aos leitores, o Ler para (se) Informar, que tem como objetivo estimular a leitura de livros paradidáticos com temas relevantes para a sociedade, principalmente para os interessados no TEA.

\section{DISCUSSÃO}

Efeitos da utilização da música no projeto Criar para Informar

Eventos são manifestações que permitem a interseção de falas, tempos e ações. São simultâneos e descontínuos, exibindo gestos e atitudes que percorrem o instante da apresentação (PINTO, 2019). 
Pode-se concluir, a partir deste pensamento, que a música, por si só, representa um evento. Ela permite, através de palavras, a interseção de sentimentos e/ou pensamentos entre diferentes indivíduos. Sua introdução na realização de congressos, palestras e outras reuniões sociais/acadêmicas é comum, e o motivo para tal é a interposição psíquica que ocorre com a "quebra" do momento da transmissão de informação e a introdução de outro momento, que tende a resgatar a atenção do público através de elementos que geram engajamento.

\section{Efeitos das mídias digitais no projeto Criar para Informar}

As divulgações nas mídias digitais representam uma mudança nas relações sociais da comunidade contemporânea, mediando os novos fluxos de comunicação no ciberespaço, por meio de um instrumento desenvolvido dentro do meio acadêmico. Instrumentos como o projeto "GENIT informa" facilitam o acesso à informação e criam novas possibilidades de interação e comunicação; são tecnologias desenvolvidas por universitários que fazem surgir novas maneiras de aprender em contextos variados, criando uma relação entre o mundo virtual e o mundo real, objetivando desenvolver uma colaboração entre quem ensina e quem aprende em todos os níveis, visando a educação permanente dos sujeitos e o ensino à distância (COSTA et al., 2015).

A extensão universitária tem como propósito assistir a sociedade por meio da concretização do conhecimento apreendido em sala de aula. É um pilar essencial, pois a sua existência transporta o aprendizado para onde há carência deste, beneficiando a população e a comunidade acadêmica, cultivando mudança social (RODRIGUES et al., 2013). Seu surgimento está demarcado no século XIX, na Inglaterra e, desde então, direciona novos caminhos para a sociedade e promove a educação continuada. No contexto atual, é um método amplamente utilizado pelas universidades públicas e privadas, a fim de efetivar o compromisso social (RODRIGUES et al., 2013).

Foi a primeira vez em que a participante do projeto trabalhou com o público virtual e com a divulgação de informações sobre o TEA em redes sociais. Divulgar informações a fim de alcançar o maior número de pessoas, utilizando a internet como ferramenta é mais fácil do que divulgar de forma física, tendo em vista que ao publicar o conteúdo, no mesmo instante, estará disponível para qualquer pessoa do mundo acessar. A construção da publicação, desde o layout das figuras até a montagem do texto, agrega valor a quem está envolvido nesse processo de produção, pois anexa conhecimento, experiência e maturidade.

O processo de investigação diz respeito a busca por informações que serão a matéria-prima do material publicado. Consiste na busca por artigos, livros, entre outros 
documentos, que estejam disponíveis nas bases de dados e que tenha passado por um rigoroso processo de avaliação antes de ser publicado, a fim de evitar a divulgação de informações duvidosas.

A principal dificuldade está no processo de filtragem de informações. Notícias falsas instalam-se no mundo virtual diariamente. A maior parte dos usuários não consegue distinguir uma notícia falsa de uma notícia verdadeira. Logo, o profissional que deseja levar notícia verídica e de qualidade aos consumidores de informação, necessita ter controle rígido sobre o material coletado.

Todos os anos, novos artigos científicos são publicados, no entanto, a divulgação científica em massa torna-se pouco acessível à comunidade leiga, visto que boa parte da esfera social não passa pelo correto processo de aprendizagem usado durante a busca científica, como: utilizar palavras-chave, acessar bases de dados compiladoras de artigos, fazer a busca por um jornal ou revista científica online, entre outras práticas (PEREIRA et al., 2015; FILIPIN et al., 2014). Como resultado, a satisfação do público pela busca do conhecimento científico decresce, aproximando-os mais de informações que a indústria de massa despeja no espaço digital, muitas vezes falsas ou sem referências (FILIPIN et al., 2014).

Outrora, profissionais e acadêmicos da saúde participavam da mídia através de colunas em jornais e entrevistas no rádio e na televisão, o que constituía parte importante do jornalismo científico. Com o passar do tempo, o interesse da população por temas da saúde foi crescendo proporcionalmente à quantidade de dúvidas no que se refere aos sintomas, diagnósticos e tratamentos do grande acervo de patologias que acometem a civilização. Sendo assim, os profissionais de saúde se adaptam às reivindicações populacionais através da atualização dos seus instrumentos de comunicação, ou seja, integrando e adequando os jornais, revistas, rádio e televisão ao campo virtual (TRIGO, 2017).

\section{CONSIDERAÇÕES FINAIS}

A introdução de um elemento artístico e a participação em eventos públicos se mostraram como ferramentas eficazes para uma comunicação e conscientização sobre o Transtorno do Espectro Autista, sendo, dessa forma, uma prática que merece ser replicada em outros eventos. 
Além disso, o material digital construído pela equipe GENIT foi amplamente visualizado nas redes sociais, comprovando a eficácia do método e testemunhando a relevância de disseminar informações principalmente que dizem respeito ao TEA para população.

Através de textos e imagens, uma pequena parcela de informações sobre o TEA foi divulgada, afinal o projeto ainda se encontra em fase inicial e tem como objetivo o aprimoramento e a contínua difusão de mais conteúdos relevantes e que possam ser úteis à população.

Este relato é particularmente importante, para divulgar informações relevantes à comunidade leiga e acadêmica, para instigar outros estudantes na construção de experiências semelhantes e por se tratar de uma forma de divulgar informações a todos, independente de classe social, econômica, cultural ou regional.

\section{AGRADECIMENTOS}

Agradecemos a empresa iNEXTTO comunicação e ao GENIT (Grupo de Estudos em Neuroinflamção e Neurotoxicologia), vinculado a Universidade Estadual do Ceará.

\section{CONTRIBUIÇÕES DE CADA AUTOR}

(A) concepção, planejamento, análise ou interpretação dos dados: G.F.A., T.P.R.B. e N.O.P.; (B) redação do artigo ou sua revisão intelectual crítica: G.F.A., N.O.P., L.L.S., J.C.C., R.M.F. e G.B.M.R.; (C) responsabilidade pela aprovação final para publicação: G.F.A. 


\section{REFERÊNCIAS}

ALlEGRETTI, S. M. M.; HESSEL, A. M. D.; HARDAGH, C. C.; SILVA, J. E. D. Aprendizagem nas redes sociais virtuais: o potencial da conectividade em dois cenários. Revista contemporaneidade, educação e tecnologia, v. 1, n. 2, p.54-60, 2012. Disponível em:

https://revistacontemporaneidadeeducacaoetecnologia02.files.wordpress.com/2012/04/pucs p_2012.pdf.

ÁVILA, C. P. A música como ferramenta inclusiva do aluno com TEA: Intervenção terapêutica aliada à Educação Musical. Música e inclusão. 2015. Disponível em: https://musicaeinclusao.wordpress.com/category/artigos/page/2/.

CERIGATTO, M. P.; CASARIN, H. D. C. S. As mídias como fonte de informação: aspectos para uma avaliação crítica. Revista Brasileira de Biblioteconomia e Documentação, v. 13, p. 155-176, 2017. Disponível em: https://rbbd.febab.org.br/rbbd/article/view/685.

COSTA, S. R. S.; DUQUEVIZ, B. C.; PEDROZA, R. L. S. Tecnologias Digitais como instrumentos mediadores da aprendizagem dos nativos digitais. Revista Psicologia Escolar e Educacional, v. 19, n. 3, p. 603-610. 2015. Disponível em: http://www.scielo.br/scielo.php?script=sci_abstract\&pid=S141385572015000300603\&lng $=\mathrm{pt} \& \mathrm{nrm}=\mathrm{iso} \& \mathrm{tlng}=\mathrm{pt}$.

FILIPIN, G.; NUNES, T.; MARTINS, A.; SOSA, P.; MELLO-CARPES, P. Neuroblitz: uma proposta de divulgação da neurociência na escola. Revista Ciência em Extensão, v. 10, n. 3, p. 69-76, 2014. Disponível em: https://ojs.unesp.br/index.php/revista_proex/article/view/1098.

INSTITUTO Brasileiro de Geografia e Estatística (IBGE). Uso de internet, televisão e celular no Brasil. Disponível em: https://educa.ibge.gov.br/jovens/materiasespeciais/20787-uso-de-internet-televisao-e-celular-no-brasil.html.

LUCENA, S. Culturas digitais e tecnologias móveis na educação. Educar em Revista, v. 59, p. 277-290, 2016. Disponível em: https://dx.doi.org/10.1590/0104-4060.43689.

PEREIRA, P.; PEREIRA, R.; ALVES, J. Ambientes virtuais e mídias de comunicação, abordando a explosão das mídias na sociedade da informação e seu impacto na aprendizagem - o uso do WhatsApp como plataforma de m-learning. Revista Mosaico, v. 6 , n. $1, \quad$ p. $29, \quad 2016 . \quad$ Disponível em: http://editora.universidadedevassouras.edu.br/index.php/RM/article/view/130.

PINTO, T.D.O. Som e música. Questões de uma antropologia sonora. Revista de Antropologia, v. 44, n. 1, p. 222-286, 2001. Disponível em: https://www.scielo.br/scielo.php?\%20script=sci_arttext\&pid=S0034-77012001000100007.

RECUERO, R. A rede é a mensagem: Efeitos da Difusão de Informações nos Sites de Rede Social. In: VIZER, Eduardo. (Org.). Lo que McLuhan no previó. Buenos Aires: Editorial La Crujía, 2012.

RODRIGUES A.L.L.; COSTA C.L.N.D.A.; PRATA M.S.; BATALHA T.B.S.; NETO I.D.F. Contribuições da Extensão Universitária na Sociedade. Cadernos de Graduação Ciências Humanas e Sociais, v. 1, n. 2, p. 141-148, 2013. Disponível em: https://periodicos.set.edu.br/index.php/cadernohumanas/article/view/494/254. 
SAMPAIO, R. T., LOUREIRO, C. M. V.; GOMES, C. M. A. A Musicoterapia e o Transtorno do Espectro do Autismo: uma abordagem informada pelas neurociências para a prática clínica. Per Musi, v. 32, p. 137-170, 2015. Disponível em: http://www.scielo.br/scielo.php?pid=S151775992015000200137\&script=sci_abstract\&tlng $=$ pt.

SANTOS, V.; SANTOS, J. As redes sociais digitais e sua influência na sociedade e educação contemporâneas. Revista HOLOS, v. 6, p. 307, 2015. Disponível em: http://www2.ifrn.edu.br/ojs/index.php/HOLOS/article/view/1936/0.

SILVA, J. C. Eventos de música como estratégia de marketing. 2004. Trabalho de Conclusão de Curso - Faculdade de Comunicação Social, Universidade Federal de Juiz de Fora, Juiz de Fora. Disponível em: .

TRIGO, L. Youtubers da saúde: a informação de saúde sem mediação jornalística. Revista Comunicação e Inovação, v. 19, n. 39, p. 82-96, 2018. Disponível em: https://seer.uscs.edu.br/index.php/revista_comunicacao_inovacao/article/view/5031.

VIEGAS, R.; VALVERDE, F.; GODOY, M. De Gutenberg às mídias digitais: ensaio sobre uma breve história da tecnologia. Revista de Estudos de Gestão, Informação e Tecnologia, v. $8, \quad \mathrm{n} . \quad 2$, p.43-53, 2018. Disponível em: http://www.fatecitaqua.edu.br/revista/index.php/regit/article/view/R8-ART2. 